\title{
A influência do género nas salas de aulas de ciências: um estudo com docentes e estudantes de $9^{\circ}$ ano
}

\author{
Margarida Oliveira a \\ Pedro Reis ${ }^{b}$ \\ Luís Tinoca ${ }^{c}$
}

\section{Resumo}

Integrando uma investigação mais vasta sobre a influência do género no ensino e na aprendizagem das ciências, procede-se aqui à análise dos dados obtidos a partir de questionários aplicados a estudantes de $9^{\circ}$ ano (com idades de 14 a 15 anos) e docentes de ciências. Procurou-se conhecer quais os modos de aprendizagem preferidos por estudantes e quais as estratégias de ensino desenvolvidas por docentes de ciências. Conclui-se que, apesar de se registarem algumas diferenças entre moças e moços, estas diferenças se tornam mais acentuadas quando se comparam as preferências manifestadas dentro de cada um destes grupos ou quando se comparam as preferências do grupo de estudantes com as práticas docentes.

Palavras-chave: Gênero. Estereótipo. Ensino das ciências. Estratégias de ensino e aprendizagem.

\section{Introdução}

O estudo apresentado integra uma investigação mais vasta desenvolvida no âmbito de um doutoramento na área da didática das ciências, em que se espera construir conhecimento sobre o modo como os estereótipos de gênero influenciam o ensino e a aprendizagem das ciências e de que forma condicionam as opções por carreiras científicas. Tratando-se de um estudo com uma metodologia que recorre a métodos mistos, o que agora se refere são parte dos resultados da primeira parte do estudo, em que se procedeu à recolha e tratamento de dados de natureza quantitativa através de questionário junto de estudantes de $9^{\circ}$ ano

\footnotetext{
a Universidade de Lisboa, Instituto de Educação. Lisboa, Portugal.

b Universidade de Lisboa, Instituto de Educação. Lisboa, Portugal.

c Universidade de Lisboa, Instituto de Educação. Lisboa, Portugal.
} 
(com idades de 14 a 15 anos) e docentes de ciências, das disciplinas de Ciências Naturais e Físico-Química.

Nesta etapa do estudo pretendeu-se dar resposta a uma questão abrangente: Que diferenças e semelhanças surgem no processo de ensino e aprendizagem das ciências em função do gênero?

\section{Enquadramento teórico}

É consensual que vivemos tempos de uma maior equidade entre os gêneros no que respeita ao acesso à educação e ao emprego, mas assimetrias acentuadas registam-se ainda quando consideramos os domínios das Ciências, Engenharias, Tecnologias e Matemáticas. A Comissão Europeia, no relatório She Figures 2009 - Statistic and Indicators on Gender Equality on Science (EUROPEAN COMMISSION, 2009), refere que 45\% dos doutoramentos obtidos em 2006 são de mulheres, equiparando ou ultrapassando os números relativos aos homens, exceto nas áreas das Ciências, Matemática e Computação (41\%) e Engenharias, Manufaturação e Construção (25\%). O relatório refere ainda que apenas 30\% das mulheres da União Europeia seguem carreiras científicas. No campo da investigação científica, Portugal destaca-se pela positiva, apresentando um valor de $44 \%$ de cientistas mulheres, encontrando-se este valor a aumentar com uma taxa superior à dos homens (EUROPEAN COMMISSION, 2009). No entanto, quando se analisa a representação de homens e mulheres nas diferentes áreas científicas, continuam a registar-se, à semelhança do que acontece nos restantes países da União Europeia, valores mais baixos para as mulheres nas áreas das engenharias e tecnologias.

Assim, e apesar das estatísticas revelarem que as raparigas apresentam na generalidade um sucesso académico superior ao dos rapazes, esta melhoria de desempenho parece ainda não se repercutir na participação das mulheres no empreendimento científico que continua a ser inferior ao que se poderia esperar tendo em conta a massa crítica existente (PÉREZ SEDEÑO, 2006).

As opções profissionais pelas carreiras científicas parecem ser influenciadas pelas experiências vivenciadas ao longo do percurso escolar, nomeadamente pelo sucesso nas disciplinas das ciências e matemática. Gurian e Ballew (2003) avançam com diferenças biológicas entre os sexos, que se traduzem em diferentes capacidades e estilos de aprendizagem nos moços e nas moças, para justificar os resultados diferenciais nas ciências e matemática dos dois géneros. Os autores referem, por exemplo, que as moças têm um melhor desempenho num ambiente de aprendizagem cooperativo, e que os moços têm melhores desempenhos em ambientes de aprendizagem mais competitivos. 
No entanto, como refere Pérez Sedeño (2006), o aumento registado, nas duas últimas décadas, no número de mulheres em carreiras científicas, e o facto de se assinalarem diferenças acentuadas entre países, vêm colocar em causa a tese geneticista, que valoriza as diferenças naturais nos sexos para explicar diferenças nos comportamentos e capacidades, e apoiar teses sociológicas que apontam os papéis atribuídos a cada gênero pela sociedade como estando na origem das diferenças registadas.

Deste modo, não nos poderemos centrar apenas nas questões do sexo, que nos reportam para as diferenças biológicas entre homens e mulheres, mas, antes, para as questões de gênero. Reconhecendo a importância do contexto sociocultural e histórico na construção relacional do conceito de gênero, situar-nos-emos na definição apresentada por Connell (2009): "Gênero é a estrutura das relações sociais que se centra nas questões da reprodução, e o conjunto de práticas que trazem as diferenças reprodutivas corporais para o processo social” (p. 11).

Certa de que as questões sociais e culturais que caracterizam as diferentes épocas têm tido um enorme peso nas diferenças geradas assume-se, como ponto de partida, que a biologia e a socialização não são alternativas contraditórias mas ambas necessárias para explicar as diferenças que surgem entre rapazes e raparigas nas formas como aprendem ciências, nas expetativas que evidenciam perante o conhecimento científico, ou mesmo nas suas futuras opções profissionais em carreiras científicas.

A evolução que se regista no número de mulheres que optam por carreiras científicas não será alheia ao esforço desenvolvido por feministas, que, desde a década de 70 do século passado, avançaram com pesquisas, nomeadamente sobre ciência e gênero. Uma das áreas mais importantes de pesquisa constitui o ensino da ciência e tecnologia e a transformação dos currículos (GONZÁLEZ GARCIA; PÉREZ SEDEÑO, 2002), centrando-se nas respostas ao que ensinar e como fazê-lo. Na resposta ao que ensinar, as propostas vão no sentido de alteração dos conteúdos curriculares e pelo cuidado em integrar modelos femininos que as alunas possam seguir. No que se refere ao como, passa por contrariar um "currículo oculto" que resulta da diferente forma com que docentes interatuam com alunos e alunas, na linguagem que se usa ou mesmo nos materiais que se selecionam. Também Silva e Saavedra (2009) referem que "o currículo oculto pode reforçar os estereótipos de género que operam subtilmente sobre os processos de socialização das alunas e dos alunos de forma tão ou mais eficaz quanto o currículo formal" (p. 65). Acrescenta-se que docentes das disciplinas científicas interatuam mais com os alunos do que com as alunas, discriminando-os de forma positiva, facto que se acentua à medida que se avança na escolaridade. As diferentes expetativas que 
o grupo de docentes possui das capacidades e possibilidades de ambos os sexos leva-os a que, consciente ou inconscientemente, valorizem uma formação científica mais para os alunos do que para as alunas, explicando o êxito dos moços pela sua inteligência e o das moças pelo seu esforço (SILVA; SAAVEDRA, 2009).

Outra das áreas de interesse, nos estudos de gênero, prende-se com os resultados diferenciais que moços e moças evidenciam nas aprendizagens de diferentes disciplinas, nomeadamente nas ciências e na matemática, tradicionalmente consideradas áreas masculinas. Na tentativa de encontrar razões que levem a perceber por que razão as moças não são, geralmente, tão boas alunas, a ciências, Harwell (2000) desenvolveu um estudo em que os resultados, que se revelam consistentes com pesquisas anteriores, indicam que elas têm uma noção simplista de ciência - 94\% das moças considera a ciência como uma coleção de factos e de produtos intelectuais conjugados com uma certa maneira de executar procedimentos empíricos. Os resultados também sugerem haver contradição entre a forma como são percecionadas as experiências de aprendizagem e as perceções das moças sobre a maneira como aprendem melhor ciência. Por outro lado, quando o estudo cruza estes dados com outros derivados das respostas à questão - O que os professores e a escola deviam fazer para aprenderes melhor ciência? - as respostas apontam maioritariamente para a preferência por estratégias ativas, projetos, pesquisas, visitas de estudo, trabalho de campo, alinhando-se no modelo epistemológico construtivista. No entanto, estas preferências manifestadas pelas alunas estavam em desacordo com as tarefas que lhes eram propostas em sala de aula, referindo-se à maioria, cerca de $80 \%$, como aprendentes passivas, e apenas $47 \%$ referia que as(os) docentes desenvolviam outro tipo de atividades tais como demonstrações, trabalho experimental ou de campo. A autora acaba por concluir que é necessário continuar a pesquisa na área, pois os resultados apontam para que as estratégias, consideradas pelas moças como as melhores para aprender ciência, são neutras quanto ao gênero, já que estão de acordo com vários modelos atuais de reformas do ensino que as preconizam como sendo as mais adequadas para o ensino das ciências para todos. Também Jones, Howe e Rua (2000) reforçam a ideia de que uma maior riqueza em experiências nas diversas áreas das ciências ajudará os alunos a ver a ciência como relevante, interessante e excitante, lamentando a realidade que encontram nas práticas docentes, fazendo-os perspetivar que esta mudança estará longe de ser conseguida.

Por outro lado, a pesquisa na área da psicologia tem mostrado que a motivação é um fator crucial no desempenho cognitivo e um dos focos de estudo prende-se com as relações entre interesse, aprendizagem e sucesso. Estudos longitudinais sugerem uma diminuição no interesse dos alunos pelos assuntos escolares à medida que avançam na escolaridade, sendo o declínio no interesse "mais evidente nas áreas da física, química e matemática, parecendo mais pronunciado para as moças do que para os moços" (HIDI; RENNINGER; KRAPP, 2004, p. 93). Esta perda de interesse parece 
dever-se, pelo menos em parte, à falta de um ambiente capaz de manter e desenvolver o interesse nas(os) estudantes. A cultura da escola pode fazer uma enorme diferença a este nível, sobretudo através do papel das(os) docentes que são uma peça essencial para, com a sua ação, ajudar a promover, nas(os) estudantes, o interesse por um conteúdo ou o gosto pela aprendizagem em geral (HIDI; RENNINGER; KRAPP, 2004). As(Os) docentes são os primeiros agentes de mudança na escola, mas têm de contar não só com os condicionalismos exteriores que vão encontrando, mas também com a sua própria história como alunas(os), a maioria produto de um ensino transmissivo. O passado fornece os modelos mentais de como ensinar, condicionando de forma poderosa a prática pedagógica, e esses modelos tornam-se mais significativos na planificação das suas lições do que os modelos das atuais teorias instrucionais (WINDSCHITL, 2002) apoiadas pelos resultados da investigação realizada na área da didática das ciências nestas últimas quatro décadas.

\section{Metodologia}

\subsection{Os instrumentos}

Tendo em conta que se pretendia recolher dados junto de estudantes e docentes que pudessem ser posteriormente analisados em conjunto, construíram-se dois questionários, um para estudantes e um para docentes, com uma estrutura similar. Para identificar as preferências de aprendizagem de estudantes, recorreu-se a um conjunto de 30 itens do questionário, solicitando aos inquiridos a opção por um dos quatro graus de uma escala (1 - não gosto, 2 - gosto pouco, 3 - gosto, 4 - gosto muito). No sentido de identificar as práticas docentes, o questionário dirigido a docentes incluiu os mesmos 30 itens com uma escala de quatro graus (1-nunca, 2 -pouco frequente, 3 -frequente, 4 -sempre).

Os questionários inicialmente desenvolvidos foram validados por um conjunto de seis investigadores. Com o seu contributo, foram introduzidas alterações aos documentos iniciais, nomeadamente ao nível da sequência das questões e à natureza da linguagem, visando à diminuição da interferência dos estereótipos de gênero nas respostas. Procedeu-se posteriormente a um estudo preliminar de forma a perceber se a leitura que estudantes e docentes faziam das questões correspondia ao pensado pela pesquisadora e se a extensão era adequada, o que se veio a confirmar no grupo de estudo.

\subsection{A amostra}

O estudo desenvolveu-se na região do Médio Tejo (Nuts III), uma das 25 regiões administrativas com fins estatísticos de Portugal. Constituíram a amostra uma 
turma de $9^{\circ}$ ano do ensino regular (estudantes com idades entre os 14 e 15 anos) de cada uma das 25 escolas com $3^{\circ}$ ciclo (que reúne o $7^{\circ}, 8^{\circ}$ e $9^{\circ}$ ano de escolaridade) e a totalidade de docentes de Ciências Naturais e Físico-Química que lecionavam as disciplinas a todas as turmas de $9^{\circ}$ ano nas respetivas escolas.

A aplicação dos questionários aos alunos foi feita pela pesquisadora num espaço de aula acordado com a direção de cada escola e, nos casos em que tal se revelou inviável por questões de horário ou indisponibilidade da direção, a aplicação foi feita por docentes das turmas após encontro preparatório com a pesquisadora. Os questionários para docentes foram entregues às direções, solicitando-se a entrega e recolha junto de cada docente participante do estudo. A recolha de dados decorreu durante o último mês do ano letivo de 2013 e de 2014, procurando-se o momento em que alunas e alunos tivessem uma ideia mais definida do percurso escolar que pretendiam prosseguir.

A amostra de estudantes compreende, num total de 523, 289 alunas e 234 alunos, com idades entre os 13 e os 18 anos, mas com predominância dos 14 e 15 anos. Não se regista uma diferença estatisticamente significativa entre o sexo e a idade. Embora se registem ligeiras diferenças entre a distribuição dos níveis obtidos por estudantes em Ciências Naturais e Físico-Química, não se regista uma diferença significativa entre o sexo e os níveis obtidos nestas disciplinas de ciências. Das variáveis de caracterização estudadas, a que apresenta um maior número de itens com diferença estatisticamente significativa, utilizando como valor de referência o $p<0,05$, é o sexo. A opção por um percurso na área das ciências ao nível do ensino secundário é tomada, na amostra em estudo, de forma equivalente por alunos $(41,5 \%)$ e alunas $(41,9 \%)$.

$\mathrm{Na}$ amostra de docentes, que conta com um total de 77 casos, 63 são mulheres e 14 são homens, tendo, no grupo de itens aqui discutidos, sido encontrada uma diferença considerada estatisticamente significativa em apenas um deles, conforme se terá oportunidade de referir.

Num total de 571 alunos amostrados, 28 não responderam ao questionário, por não terem sido autorizados pelo respetivo encarregado de educação ou por se encontrarem ausentes da sala de aula no momento da realização do questionário. Foram ainda considerados não válidos 10 dos questionários recolhidos, por não terem sido assinaladas todas as questões ou por se verificar não haver diferenciação na resposta, contandose com um total de 523 questionários válidos. Em relação ao grupo de docentes, a amostra compreendia 85 participantes, à qual não responderam seis docentes, e dois questionários não foram considerados válidos por não se encontrarem assinaladas todas as respostas, perfazendo um total de 77 questionários válidos. 


\section{Leitura e discussão dos resultados}

Após recolha de dados através dos questionários, procedeu-se às análises descritivas, correlacionais e comparativas recorrendo ao software SPSS (versão 21).

$\mathrm{O}$ alfa de Chronbach encontrado para o conjunto dos 30 itens considerados foi de $r=0,812$ para estudantes e de $r=0,837$ para docentes, considerando-se, deste modo, haver consistência interna dos itens, ou seja, uma boa fiabilidade dos dados obtidos (MAROCO; GARCIA-MARQUES, 2006). A procura de diferenças estatísticas nas respostas dos diferentes grupos da amostra fez-se através do teste Qui-quadrado de Pearson, considerando $p \leq 0,050$. O teste do Qui-Quadrado é um teste não paramétrico, que permite a comparação da distribuição de frequências entre dois ou mais grupos, mesmo que a sua distribuição não seja normal, e que se adequa à análise de dados categoriais (BISPO; MAROCO, 2005). O Quadro contém as frequências e os valores relevantes de $p$ calculados quando comparadas as opções de alunas e alunos, bem como quando comparadas as opções do grupo de estudantes com as do grupo de docentes.

Para cada um dos 30 itens foi calculado o valor médio, posteriormente utilizado para a construção da representação gráfica dos resultados, facilitando a visualização dos dados.

Os itens foram agrupados, para análise, nas seguintes categorias: Atividades, Organização, Ambiente, Interação e Atitudes.

Foram agrupados na categoria Atividades dez itens, sendo que cada um deles se refere a uma atividade passível de ser realizada nas salas de aulas de ciências. Os valores médios calculados encontram-se na Figura 1.

Se tivermos em conta o sexo, não se identificam opções com diferenças estatisticamente significativas (considerando $p<0,050$ ) nas opções de docentes. No grupo de estudantes apenas em dois dos itens se registam estas diferenças pois as moças parecem gostar mais de resolver fichas de trabalho $(p=0,004)$ e os moços de fazer pesquisas na internet $(p=0,003)$. No entanto, se compararmos as opções que traduzem o gosto de estudantes por determinada atividade de sala de aula e as opções que traduzem as práticas docentes que lhes são oferecidas, encontramos uma distribuição de opções com diferenças estatisticamente significativas para todos os itens considerados.

As opções de docentes sugerem uma prática mais centrada na exposição dos assuntos em estudo e na resolução de fichas de trabalho. Já as alunas e os 
alunos mostram preferência por atividades como o trabalho de laboratório, mas sem a elaboração do relatório das atividades práticas desenvolvidas, pela pesquisa na internet, o visionamento e a discussão de filmes sobre os assuntos da aula, visitas de estudo e saídas de campo e a realização de jogos sobre os assuntos estudados.

Este distanciamento, explicável pelo papel docente na tomada de decisões técnicopedagógicas, não deveria deixar de ter em conta as preferências de estudantes, já que se corre o risco de se ensinar ciência de forma pouco relevante ou interessante, não contribuindo para que as(os) estudantes considerem o empreendimento científico como uma área a seguir.

Foram agrupados na categoria Organização onze itens, que se referem a diferentes formas de organização que se podem encontrar na sala de aula: organização do modo de trabalho, organização da interação, organização do espaço, organização do tempo. Nesta categoria é frequente encontrar diferenças estatisticamente significativas entre as opções de moças e moços. Na Figura 2 encontram-se os valores médios calculados para cada um dos itens.

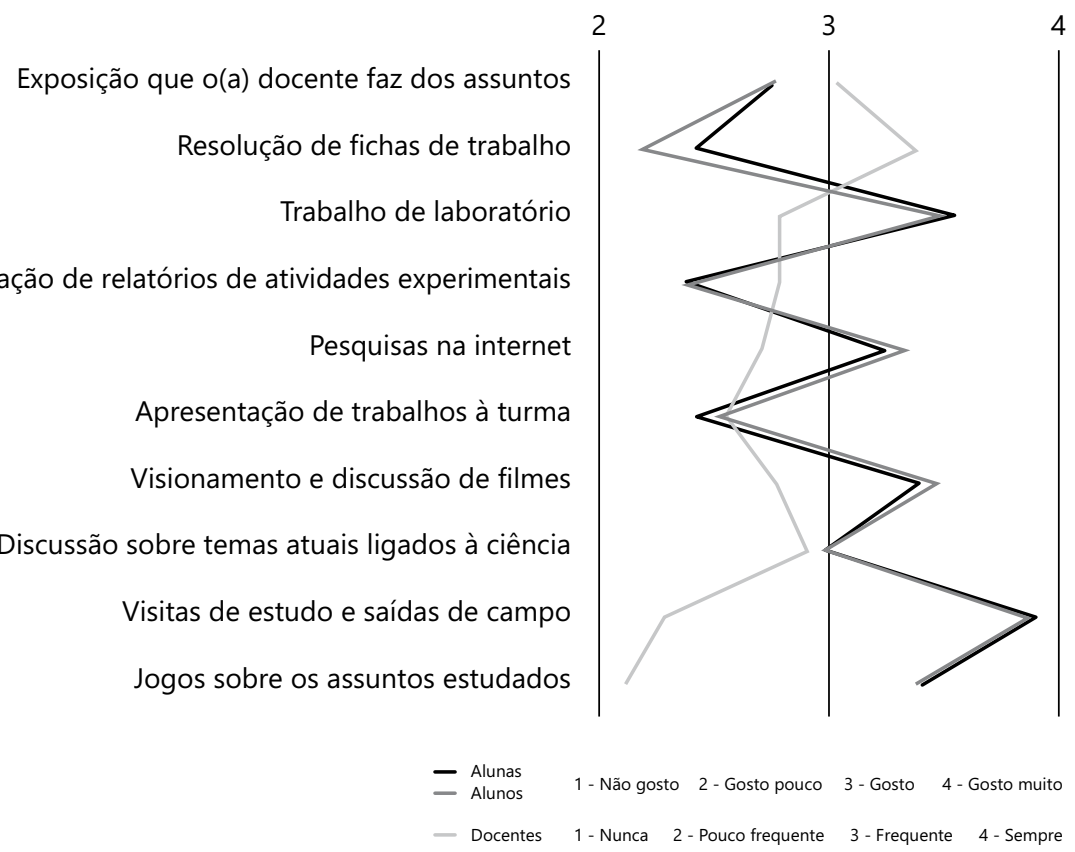

Fonte: Elaborada pelos autores (2016).

Figura 1. Valor médio das respostas na categoria Atividades. 
Os moços preferem, mais do que as moças, realizar trabalhos em que não seja necessário recorrer à escrita $(p=0,000)$ e realizar tarefas de curta duração $(p=$ $0,001)$. As moças preferem, mais do que os moços, ter o tempo necessário para concluir uma tarefa $(p=0,047)$, receber orientações do que fazer no início de uma tarefa $(p=0,002)$, ouvir as intervenções dos colegas $(p=0,001)$, realizar trabalho individual $(p=0,010)$ e ter um caderno organizado $(p=0,000)$. As opções de moços e moças sugerem que ambos gostam de responder a questões com respostas curtas, de realizar atividades que se desenvolvam ao longo de várias aulas e realizar trabalhos de grupo ou pares. As opções assinaladas maioritariamente por ambos indiciam não gostarem de escrever um texto sobre um assunto. Quando se analisam as práticas docentes e se comparam com as preferências manifestadas pelo grupo de estudantes, apenas o item "Escrever um texto sobre um assunto/Criar situações de aula para a construção de textos" não apresenta uma diferença estatisticamente significativa. Nos restantes itens, registase um maior distanciamento entre as preferências assinaladas por estudantes e as práticas docentes, havendo sete itens em que se verifica uma maior aproximação das práticas docentes às preferências das moças e apenas três itens em que as práticas docentes se aproximam das preferências dos moços.

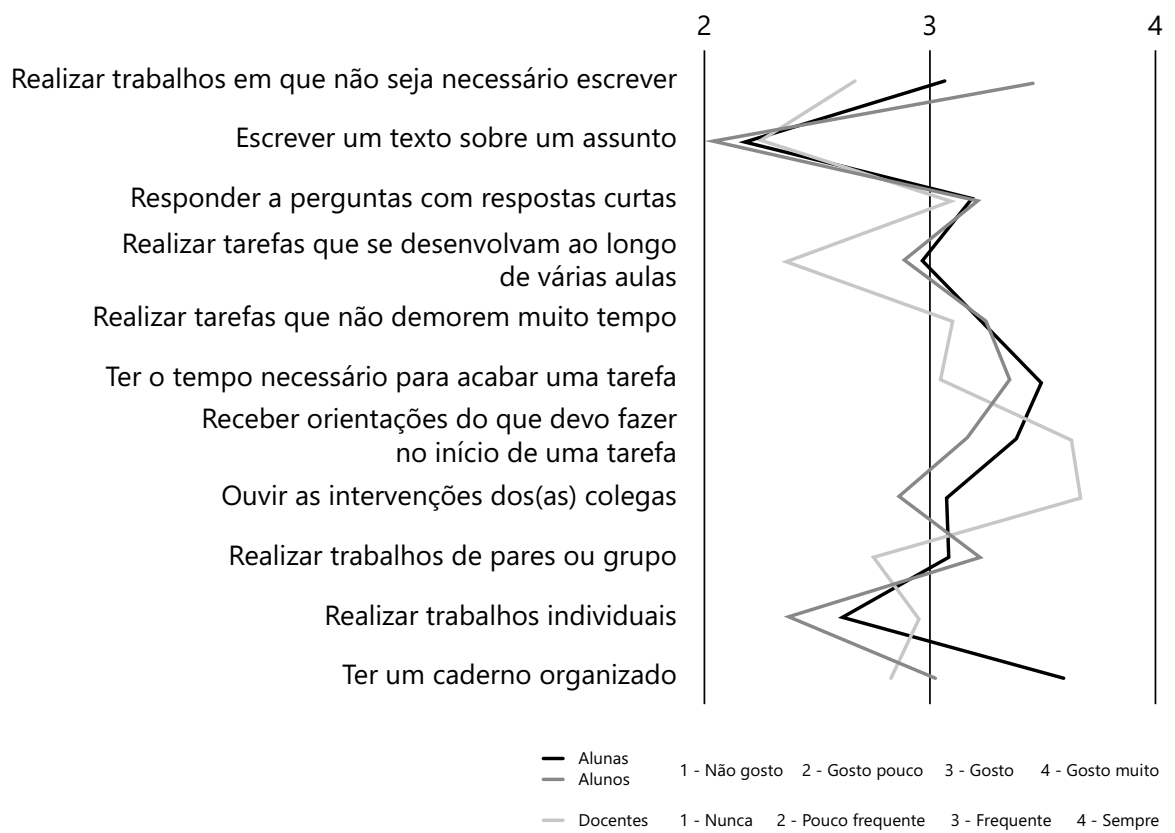

Fonte: Elaborada pelos autores (2016).

Figura 2. Valores médios das respostas na categoria Organização. 
Quanto ao Ambiente da sala de aula, incluíram-se dois itens que se referiam ao nível de bulício da sala de aula. Verifica-se uma diferença estatística significativa nas opções de moços e moças em relação aos dois itens considerados. Os valores médios calculados encontram-se na figura 3 .

As moças, à semelhança das professoras e dos professores, preferem estar na sala de aula em silêncio, o que não se confirma claramente nas preferências dos moços $(p=0,022)$. Embora a maioria dos alunos e alunas refira gostar pouco de trabalhar com algum barulho na sala de aula, verifica-se uma maior frequência de moços que prefere trabalhar com barulho na sala de aula $(p=0,006)$.

Esta é a única questão deste grupo do questionário que apresenta uma diferença estatisticamente significativa nas opções assinaladas por professoras e professores. Deste modo, verifica-se que os professores assinalam com maior frequência do que as professoras o ser frequente ter algum barulho na sala de aula $(p=0,026)$.

Na categoria Interação foram também incluídos dois itens, relativos à interacção verbal na sala de aula, nomeadamente no colocar e responder a questões. Os valores médios encontram-se representados na Figura 4.

Quanto a responder às perguntas $\mathrm{da}(\mathrm{o})$ docente, não se registam diferenças estatisticamente significativas, e as opções do grupo de estudantes concentram-se no gostar pouco ou gostar, o que não se alinha com as respostas da maioria docente que refere ser muito frequente fazer perguntas orais. Também não se registam grandes diferenças entre as opções de alunas e alunos no que se refere a colocar questões sobre os assuntos em estudo. Há, no entanto, uma discordância destas com as assinaladas por docentes já que a maioria assinala ser muito frequente fazer

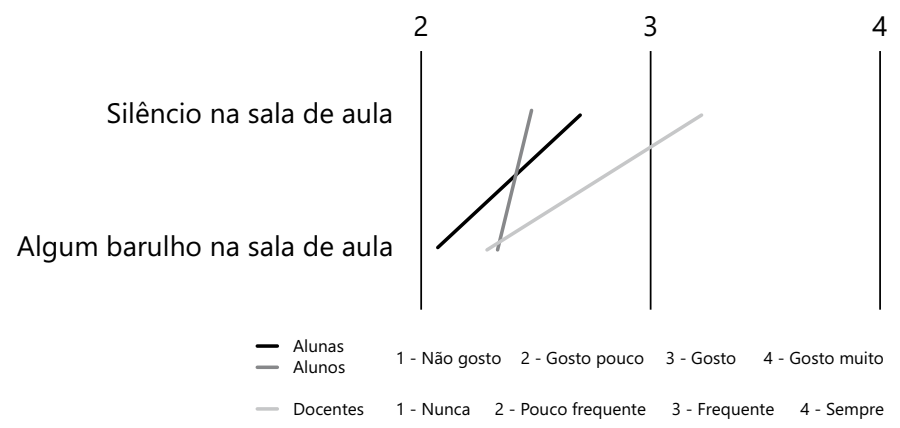

Fonte: Elaborada pelos autores (2016).

Figura 3. Valores médios das respostas na categoria Ambiente. 
perguntas sobre os assuntos em estudo, mas apenas uma pequena percentagem de estudantes refere gostar muito de responder a elas.

Cinco itens foram agrupados na categoria Atitudes, referindo-se à forma como se lida com o humor ou com a competição e a colaboração. Os valores médios das respostas encontram-se expressos na Figura 5.

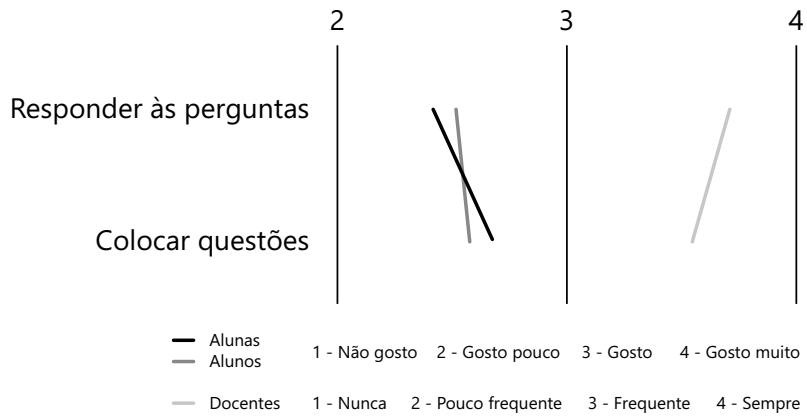

Fonte: Elaborada pelos autores (2016).

Figura 4. Valores médios das respostas na categoria Interação.

Lidar bem e aprender com situações em que o(a) docente recorre ao humor

Receber uma recompensa por terminar uma tarefa

Ver quem é o primeiro a acabar o trabalho

Esforçar-se para ter o melhor trabalho da turma

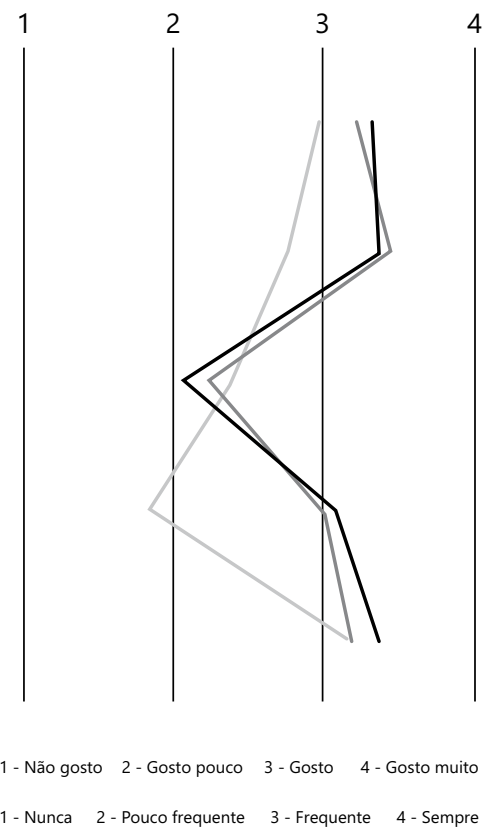

Fonte: Elaborada pelos autores (2016).

Figura 5. Valores médios nas respostas da categoria Atitudes. 
Regista-se alguma proximidade entre as opções de estudantes e docentes no que respeita ao gosto pela utilização do humor como uma provocação para promover a aprendizagem. No que respeita ao receber uma recompensa por terminar uma tarefa, há uma diferença estatisticamente significativa entre as opções de alunas e alunos, sendo que os moços gostam mais do que as moças $(p=0,035)$ de receber uma recompensa. Já no grupo de docentes, verifica-se uma frequência importante do ser pouco frequente fazê-lo. Quanto a ver quem é o primeiro a acabar o trabalho, não se registam grandes diferenças entre as opções selecionadas pelas alunas e pelos alunos, que se alinham com a opinião da maioria de docentes que refere ser uma prática pouco frequente.

Alunos e alunas selecionam frequentemente a opção de gostar de se esforçar para ter o melhor trabalho embora, no grupo de docentes seja mais frequente a opção de ser pouco frequente incentivar a competição de forma a melhorar os resultados. Há ainda a registar uma diferença estatisticamente significativa nas opções das alunas e alunos no que respeita ao colaborar com os colegas na realização das tarefas $(p=0,001)$, pois, embora ambos assinalem o gostar de colaborar com os colegas, verifica-se uma maior preferência para o fazer por parte das moças. Também as(os) docentes assinalam promover, com frequência, $o$ trabalho colaborativo, não se registando diferenças estatisticamente significativas neste item entre docentes e estudantes.

\section{Considerações finais}

Antes de partirmos para as considerações finais, será importante reforçar a ideia de que as diferenças que se encontram entre moças e moças são sempre menores do que aquelas que se encontram dentro do próprio gênero. Por outro lado, poderá ser problemático tirar conclusões sobre as comparações efetuadas entre o grupo de estudantes e o grupo de docentes já que, apesar de trabalharmos com instrumentos de recolha de dados muito semelhantes, as escalas utilizadas não são equivalentes, uma vez que no questionário de estudantes se utiliza uma escala de preferências, e, no questionário de docentes, se utiliza uma escala de frequências. Refira-se ainda que o recurso ao cálculo da média por item, para melhor visualizarmos as proximidades entre o grupo de docentes e os grupos das alunas e dos alunos, pode apresentar alguns enviesamentos decorrentes quer da transformação das escalas de preferências e de frequências numa escala ordinal, quer do fato de se registarem valores de dispersão elevada para muitos dos itens. Deverá ainda ter-se em conta de que o estudo não cruza as preferências de estudantes de um dado grupo/turma com as práticas das(os) respetivas(os) docentes, sendo os dados analisados considerando a globalidade das amostras 
de estudantes e docentes, o que poderá conduzir a algumas limitações quando se compara as preferências de estudantes com as práticas docentes.

Não esquecendo as limitações que poderão advir das situações mencionadas ou outras que poderão estar a interferir com a recolha e interpretação dos dados, estes sugerem que as atividades desenvolvidas por docentes não coincidem maioritariamente com as preferidas por estudantes, aproximando-se as opções docentes de um ensino onde a(o) aluna(o) tem um papel mais passivo e as de estudantes de um ensino onde têm um papel mais ativo. Os resultados alinhamse com os obtidos por Harwell (2000) e Jones et al. (2000). Deste modo, parece que no processo de instrução se está a negligenciar a criação de um ambiente de sala de aula capaz de suportar, ou desenvolver, o interesse de estudantes pela aprendizagem das ciências, o que, de acordo com Hidi, Renninger e Krapp (2004), pode repercutir de forma negativa no sucesso das aprendizagens e condicionar a escolha dos futuros percursos escolares de estudantes nas áreas das ciências.

A opção por um percurso na área das ciências ao nível do ensino secundário é tomada, na amostra em estudo, de forma equivalente por alunos e alunas. Significa que não é ainda ao nível do ensino secundário que elas, ou eles, se afastam das ciências. No entanto, é provável que o processo de instrução possa estar a influenciar as escolhas que são feitas por estudantes no ensino superior, deixando as raparigas mas suscetíveis aos estereótipos de gênero, levando-as a preferir as ciências biológicas às ciências físicas. Mesmo quando elas seguem cursos superiores nas áreas das ciências ditas duras, é mais provável que optem por uma carreira no ensino do que por uma carreira na investigação científica. A leitura das estatísticas de estudantes a frequentar atualmente o ensino superior em Portugal mostra que elas se encontram em maioria nas áreas como a educação, a saúde ou a proteção social; em contrapartida, encontram-se em minoria em outros cursos de ciências, matemática, informática ou engenharias (PORDATA, 2017). A dominância feminina no grupo de docentes de ciências participantes neste estudo, com uma representatividade de $81,8 \%$, pode ser bem ilustrativa de como uma carreira no ensino é uma opção maioritariamente feminina.

Na categoria Atitudes, pode encontrar-se uma aproximação ao referido por Gurian e Ballew (2003), pois, embora moços e moças refiram gostar de se empenhar para ter o melhor trabalho, elas parecem preferir um ambiente de trabalho colaborativo, enquanto eles se aproximam da preferência por um ambiente mais competitivo. Essas diferenças de atitude poderão, no entanto, não resultar de diferenças biológicas entre os sexos, como defendido por Gurian e Ballew (2003), mas dos papéis tradicionais de gênero em que somos socializadas(os). 
Tendo em conta que as(os) docentes referem promover, com frequência, o trabalho colaborativo e ser pouco frequente atribuírem recompensas pelo terminar de uma tarefa, poderemos encontrar uma vantagem para as moças já que elas manifestam preferência por um ambiente mais colaborativo e menos competitivo.

Também, nas restantes categorias, continua-se a verificar, maioritariamente, um distanciamento entre as opções de docentes e estudantes. Quando se procura a proximidade entre as práticas docentes e as preferências de moças e moços, é na categoria Organização que se torna mais evidente uma aproximação entre as opções de docentes e as das moças. Estes resultados podem sugerir que elas procuram, mais do que eles, corresponder ao que é esperado pelas(os) docentes em relação ao papel da(o) estudante. A este desempenho pode estar subjacente o estereótipo de que elas são melhores alunas porque trabalham e são mais organizadas e eles são bons alunos porque são mais inteligentes.

Considerando os dados recolhidos, não poderemos afirmar que as práticas docentes favorecem mais claramente um gênero do que o outro, havendo situações em que se identifica maior proximidade às preferências manifestadas pelas moças, e outras em que se identifica proximidade às preferências dos moços. No entanto, na maioria das situações analisadas, regista-se um distanciamento entre as práticas docentes e as preferências manifestadas por moças e moços.

Tendo em conta os resultados, afigura-se fundamental olhar para as práticas docentes que, continuando distantes das práticas defendidas pela pesquisa em didática das ciências, poderão estar a interferir de forma negativa na aprendizagem, prejudicando quer moços quer moças. Estes resultados poderão constituir-se como um espaço privilegiado de reflexão motivando as(os) docentes de ciências a repensarem as suas práticas, desenvolvendo, nas suas aulas, uma maior diversidade de situações de aprendizagem numa perspetiva CTS (Ciência, Tecnologia e Sociedade). Pretende-se um ensino das ciências que vá para lá de uma aprendizagem de conceitos, promotor de "desenvolvimento de uma cidadania responsável - uma cidadania individual e social para lidar com problemas que têm dimensões científicas e tecnológicas, num contexto que se estende para além do laboratório e das fronteiras das disciplinas" (SANTOS, 1999, p. 25), incompatível com um modelo transmissivo. Numa abordagem problemática, os problemas quotidianos poderão ser o ponto de partida para a aprendizagem dos conceitos científicos e metacientíficos: procurando a articulação dos diferentes domínios do saber, numa abordagem transdisciplinar, promovendo uma visão holística da ciência; através de uma abordagem histórica, mostrando como a ciência e a tecnologia evoluíram com a sociedade; discutindo a natureza do conhecimento 
científico, dos seus limites, da sua validade numa abordagem epistemológica. "Esta parece ser uma via promissora em termos de maior motivação intrínseca dos alunos, de melhor preparação destes para darem uma resposta mais adequada e socialmente mais correta aos problemas científico-tecnológicos e ambientais do mundo contemporâneo e ainda de desenvolvimento de formas de pensamento mais elaboradas" (CACHAPUZ; PRAIA; JORGE, 2002, p. 178).

Ao nível da formação inicial de professoras(es) há já a preocupação de formar num modelo epistemológico construtivista mas, pelos mais variados constrangimentos, ainda não se faz notar na maioria das práticas letivas. Caberá a cada docente adotar uma atitude reflexiva e, em conjunto com os seus pares, caminhar na construção de uma sala de aula que não se preocupe apenas em formar estudantes sabedores, mas sim em ajudar a desenvolver as competências que lhes permitam tornarem-se cidadãos intervenientes, capazes de mobilizar as suas competências no sentido de agir perante um mundo em constante evolução. 


\section{The influence of gender in the teaching and learning of science: a study of 9 th grade teachers and student}

\section{Abstract}

Integrating a boarder investigation about the gender influence in teaching and learning of sciences, the analysis was performed on data collected from questionnaires applied to $9^{\text {th }}$ degree students (ages 14 to 15 years), and to science teachers. The goal of investigation was to understanding the student learning mode of preference and the teaching strategies developed by sciences teachers. The study revealed, as a conclusion, the existence of some differences between young man and young women students, gender differences. Those differences were more pronounced when compared with the preferences manifested within of these groups, or even more when compared to the student group's preferences with the teaching practices.

Keywords: Gender. Stereotype. Science education. Teaching and learning strategies.

\section{La influencia del género en las clases de ciencias: un estudio con docentes y estudiantes del $3^{\circ}$ año de Secundaria $\left(9^{\circ}\right.$ ano)}

Resumen

Haciendo parte de una investigación más amplia sobre la influencia del género en la enseñanza y el aprendizaje de las la ciencias ciencia, se procede aquí al análisis de los datos obtenidos a través de cuestionarios aplicados a estudiantes del $3^{\circ}$ año de Secundaria $9^{\circ}$ grado (con 14 o 15 años de edad) y profesores de ciencias. Se procuró conocer las formas de aprendizaje preferidas de los estudiantes y las as estrategias de enseñanza utilizadas por sus profesores, concluyéndose que, aunque se registren algunas diferencias entre niños y niñas, estas diferencias se vuelven más pronunciadas cuando se comparan las preferencias expresadas dentro de cada uno de estos grupos o al comparar las preferencias del grupo de los estudiantes con las prácticas de enseñanza docentes de los profesores.

Palabras clave: Género. Estereotipo estereotipos. Educación científica. Estrategias de enseñanza y aprendizaje. 


\section{Referências}

BISPO, R.; MAROCO, J. Estatística aplicada às ciências sociais e humanas. Lisboa: Climepsi Editores, 2005.

CACHAPUZ, A.; PRAIA, J.; JORGE, M. Ciência, educação em ciência e ensino das ciências. Lisboa: Instituto de Inovação Educacional, 2002.

CONNELL, R. W. Gender: Short introduction. 2nd ed. Cambridge: Polity Press, 2009.

EUROPEAN COMMISSION. She Figures 2009 : Statistic and Indicators on Gender Equality on Science. Luxembourg: Publications Office of the European Union, 2009.

GONZÁLEZ Garcia, M.; PÉREZ SedeÑo, E. Ciencia, tecnologia y género. Revista Iberoamericana de Ciencia, Tecnologia, Sociedad e Innovación, n. 2, jan./abr. 2002. Disponível em: <http://www.oei.es/historico/revistactsi/ numero2/varios2.htm>. Acesso em 26 dez. 2011.

GURIAN, M.; BALLEW, A. C. The boys and girls learn differently: Action guide for teachears. San Francisco: Jossey-Bass, 2003.

HARWELL, S. H. In their own voices: Midlle level girl's perceptions of teaching and learning science. Journal of Science Teacher Education, v. 11, n. 3, p. 221-242, ago. 2000.

HIDI, S.; RENNINGER, K.; KRAPP, A. Interest, a motivational variable that combines affective and cognitive functioning. In: Day, D. Y.; Sternberg, R. (Ed.), Motivation, emotion, and cognition: Integrative perspectives on intellectual functioning and development. New Jersey: Lawrence Erlbaum Associates Inc. Publishers, 2004. p. 89-115.

JONES, M. G.; HOWE, A.; RUA, M. J. Gender differences in students' experiences, interests, and attitudes toward science and scientists. Science Education, v. 84, n. 2, 181-192, 2000. doi: https://doi.org/10.1002/ (SICI)1098-237X(200003)84:2<180::AID-SCE3>3.0.CO;2-X

MAROCO, J.; GARCIA-MARQUES, T. Qual a fiabilidade do Alfa de Cronbach? Questões antigas e soluções modernas?. Laboratório de Psicologia, v. 4, n. 1, 65-90, 2006. doi: https://doi.org/10.14417/lp.763

PORDATA. Base de Dados Portugal Contemporâneo. Disponível em: $<$ http://www. pordata.pt/Tema/Portugal/Educa\%C3\%A7\%C3\%A3o-17>. Acesso em: 10 jun. 2017. 
PÉREZ SEDEÑO, E. Sexos, géneros y otras espécies: Diferencias sin desigualdades. In: Lara, C. (Ed.), El segundo escalón: desequilíbrios de género en ciencia e tecnologia. Sevilha: Arcibel Editores, 2006. p. 21-42.

SANTOS, M. E. V. M. Desafios pedagógicos para o século XXI: suas raízes em forças de mudança de natureza científica, tecnológica e social. Lisboa: Livros Horizonte, 1999.

SILVA, P.; SAAVEDRA, L. Género e currículo. In: Pinto, T. (Coord.), Guião de educação, género e cidadania. $3^{\circ}$ ciclo do ensino básico. Lisboa: Comissão para a Cidadania e Igualdade do Género, 2009. p. 61-66.

WINDSCHITL, M. Framing constructivism in practice as the negotiation of dilemmas: An analysis of the conceptual, pedagogical, cultural, and political challenges facing teachers. Review of Educational Research, v. 72, n. 2, 131-175, 2002. doi: https://doi.org/10.3102/00346543072002131

\section{Informações dos autores}

Margarida Oliveira: Mestre, Doutoranda em Educação, Especialização em Ensino das Ciências, do Instituto de Educação, Universidade de Lisboa. Contato: margarida.oliveira@campus.ul.pt

Pedro Reis: Professor doutor. Professor Associado e Subdiretor do Instituto de Educação, Universidade de Lisboa, onde coordena o Programa de Doutoramento em Didática das Ciências. Contato: preis@ie.ulisboa.pt

Luís Tinoca: Professor doutor. Professor Auxiliar do Instituto de Educação, Universidade de Lisboa, onde coordena o Programa de Doutoramento em Formação de Professores. Contato: 1tinoca@ie.ulisboa.pt 


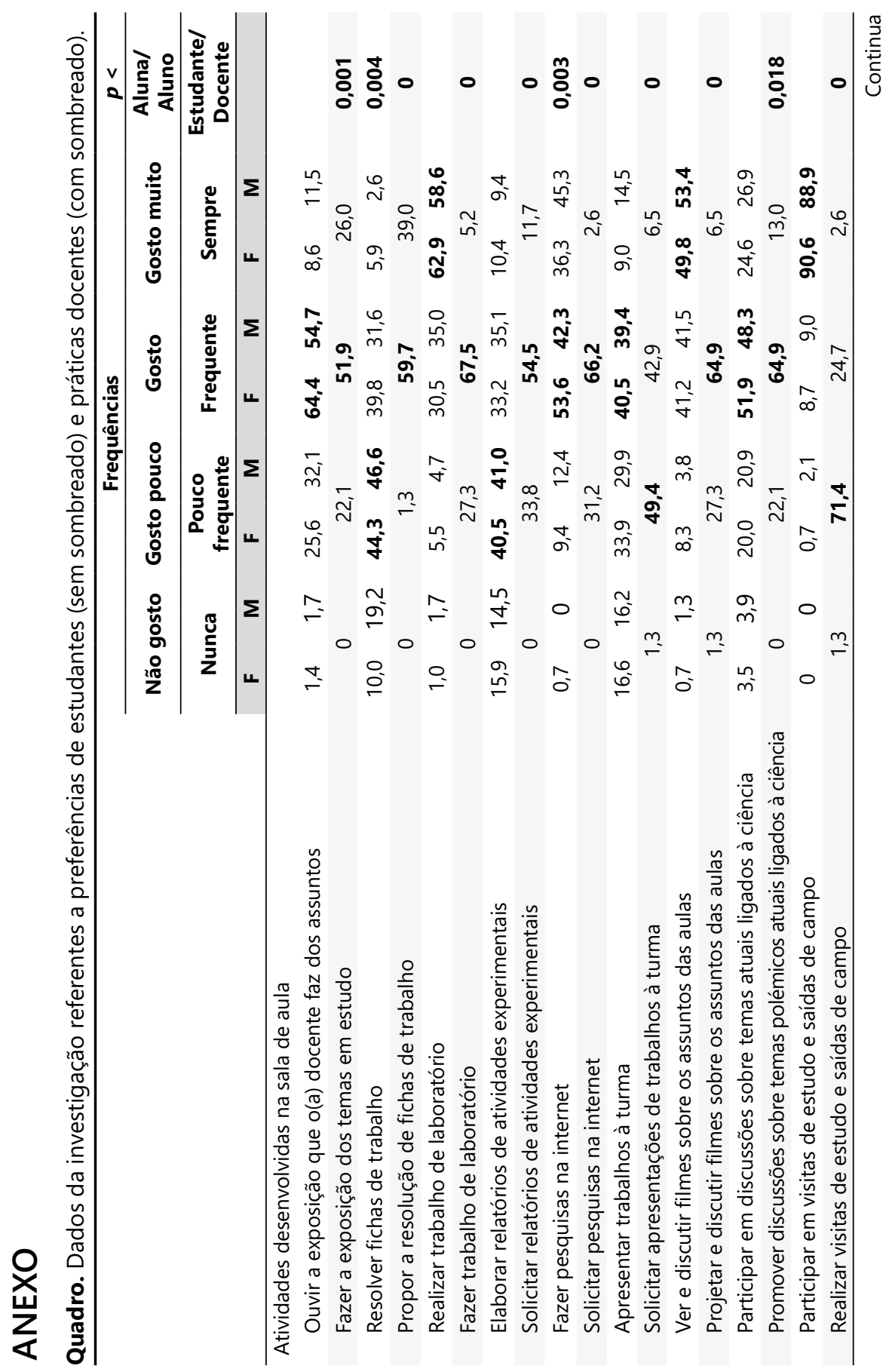




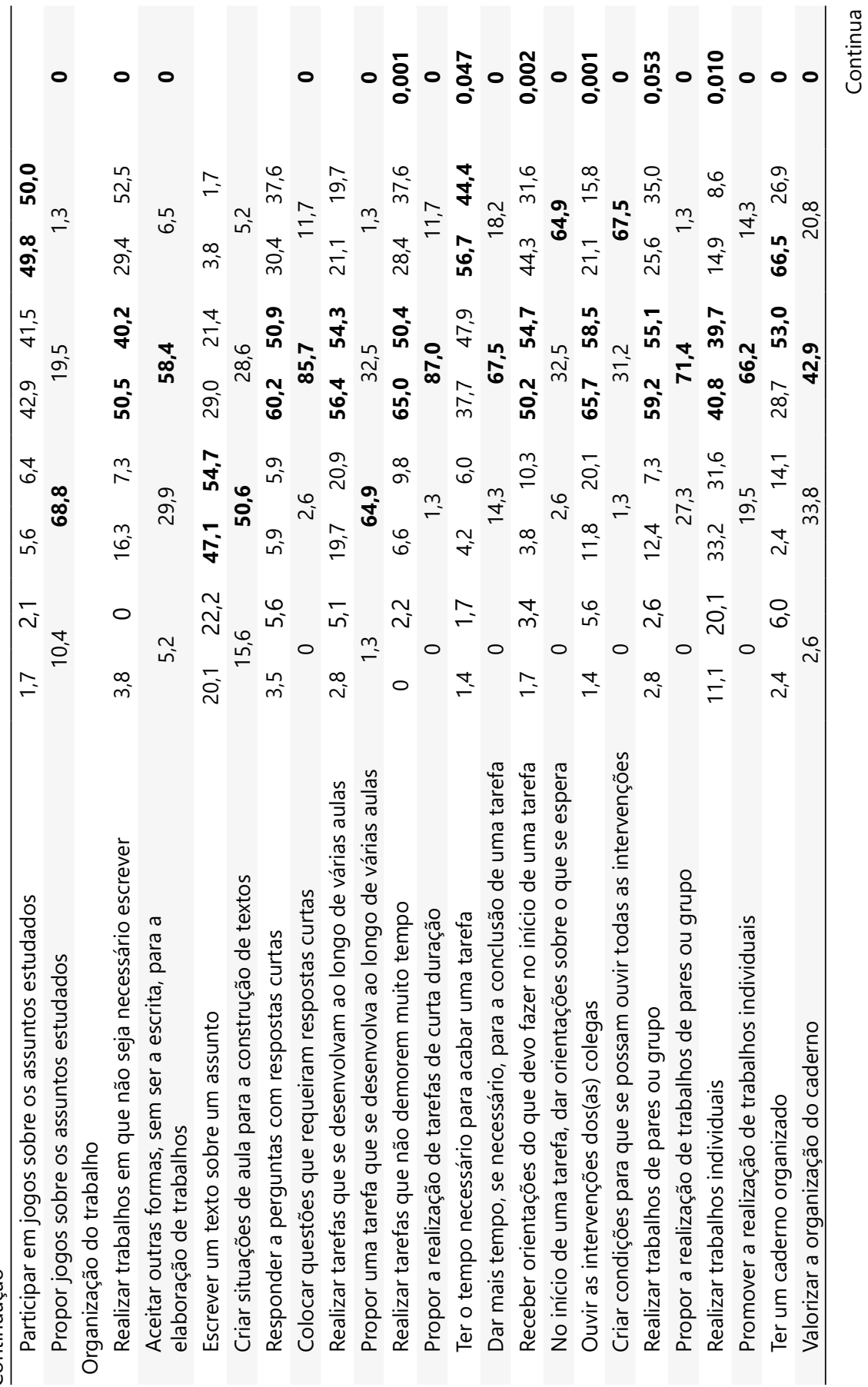




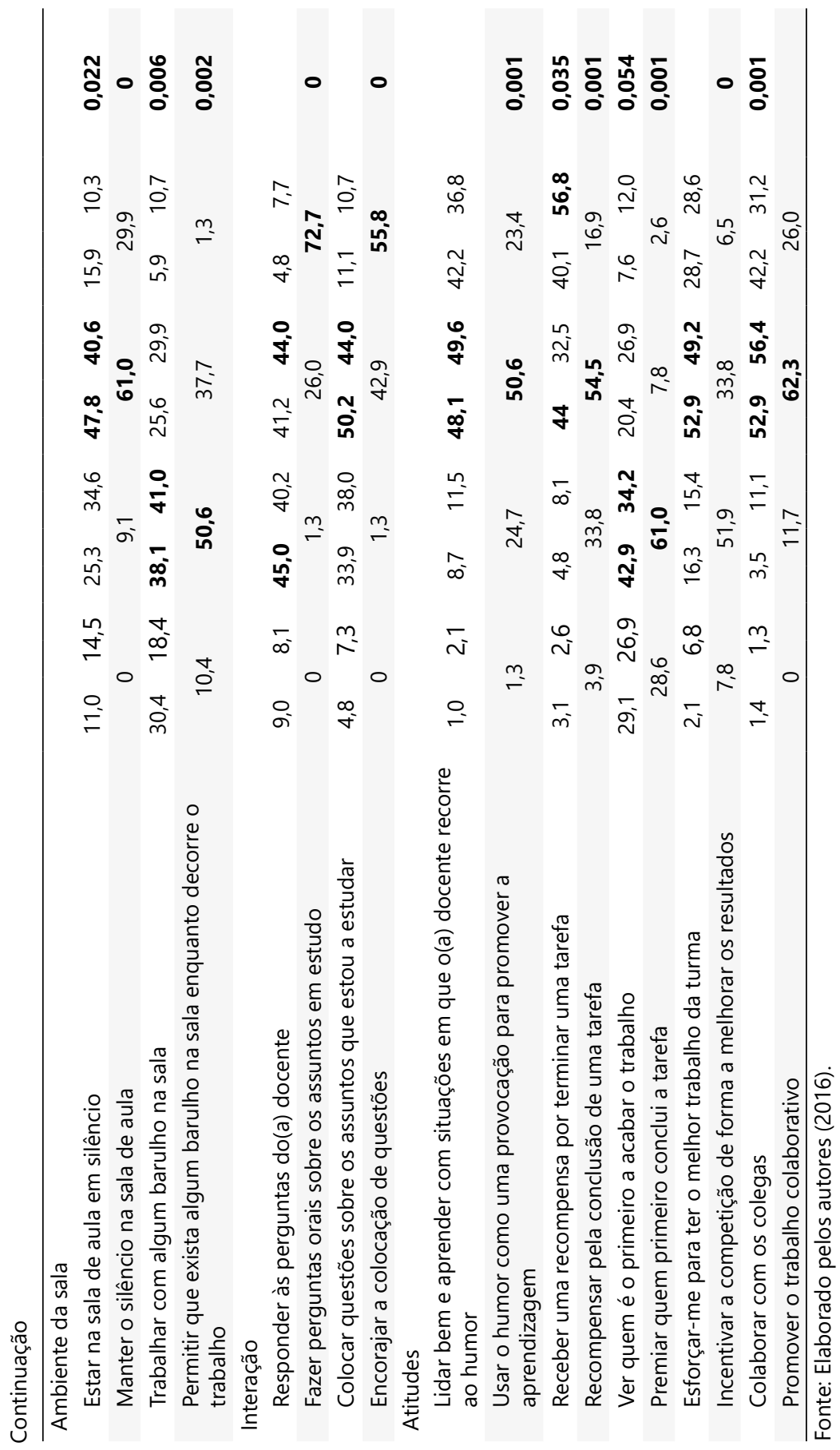

